\title{
A cross sectional study to analyse the pervasiveness and risk factors of antepartum depression in pregnant women
}

\author{
Rekha Garlapati ${ }^{1, *}$, Dhaval Kumar Rasiklal Dharani ${ }^{2}$, Manjula Rao ${ }^{3}$, Tejaswini ${ }^{4}$ \\ ${ }^{1}$ Senior Consultant, ${ }^{2,4} \mathrm{DNB}$ Resident, ${ }^{3} \mathrm{HOD}$, Dept. of Obstetrics and Gynecology, Durgabai Deshmukh Hospital and Research \\ Centre, Hyderabad, Telangana, India \\ *Corresponding Author: \\ Email: reddyreddyrekha@yahoo.in
}

Received: $17^{\text {th }}$ April, 2018

Accepted: $19^{\text {th }}$ June, 2018

\begin{abstract}
Introduction: Pregnancy being a major psychological, as well as, physiological event it is also one of the delighted moments in a women's life, but for most of them it's a time of confusion, fear, anxiety, stress and even depression, with an excess of chronic life stressors they find themselves unable to cope with the additional demands of pregnancy.

Aims and Objectives: To determine the pervasiveness and risk factors of ante partum depression in a cohort of 300 pregnant women attending outpatient department of obstetrics and gynecology at Durgabai Deshmukh Hospital and Research Centre, Hyderabad.

Settings and Design: A Prospective, observational, cross-sectional study.

Methodology: 300 pregnant women attending antenatal out patient department of Obstetrics and Gynecology at Durgabai Deshmukh hospital and research centre between April 2016 to November 2016 were screened for ante partum depression using EPDS (Edinburg postnatal depression score) questionnaire.

Statistical Analysis: Student's ' $t$ ' test was applied to analyze the data and P value $<0.05$ was considered statistically significant. Results: $22.66 \%$ i.e., 68 of 300 subjects had ante partum depression. Ante partum depression was most commonly seen in age group of 25-30 yrs. Poor family support and partner violence has statistical significance in development. Socio economic status, Region, Parity and Gestational age showed no statistical significance in our study.

Conclusion: Ante partum depression is pervasive among pregnant women in Hyderabad; due to lack of awareness, future research in this area is recommended to elucidate the impact of depression during pregnancy and associated obstetric risk factors.
\end{abstract}

Keywords: EPDS, Pregnancy, Depression, Ante partum, Risk factors.

\section{Key Messages}

1. Universal screening for APD must be incorporated into our maternal and child health programmes.

2. American College of Obstetricians and Gynaecologists (ACOG) recommends screening for depression during each trimester of pregnancy. ${ }^{1}$

3. Obstetrician must be aware of the symptoms and need to identify them early, give adequate counselling and treatment to prevent postpartum depression.

\section{Introduction}

Pregnancy is the delighted moment in a women's life, but for many of them manifest confusion, fear, anxiety, stress and even depression. Between $8 \%$ to $24 \%$ of pregnant women experiences depressive disorder during pregnancy. ${ }^{2-7}$ In 2003, approximately $13 \%$ of women were found to be on antidepressants at some point in pregnancy, a rate that has been doubled since $1999 .{ }^{8}$ By 2020 , The World Health Organization (WHO) will be identifying depressive disorders as the second leading cause of global disease burden and maternal depression is a hidden burden in developing countries. $^{9}$ The confidential enquiries into maternal deaths (CEMD, 2001) ascertains suicide as the major cause of maternal death. ${ }^{10-12}$ Maternal depression is progressively recognized as a worldwide public health issue with a negative impact on an individual's life that is far reaching, affecting work, family and the health and development of the baby. However, there are insufficient studies which analyses the associated factors and prevalence of antenatal depression in lowincome countries like India.

Despite the fact that a lot of attention has been paid to postpartum depression. It's also not rare for women to undergo any form of depression during pregnancy, termed as ante partum depression. Depression in pregnant women cannot be easily recognized as changes in mood, energy level, appetite, and cognition resemble those like associated with pregnancy. Ante partum depression generally occurs by consolidation of hormonal changes and psychological disturbances associated with pregnancy. ${ }^{13-15}$ Pregnant women undergo notable psychological changes other than physical changes such as changes in posture, sleep and eating habits may also lead to ante partum depression. ${ }^{16,17}$

In addition to having a history of depression, other risk factors for ante partum depression include lack of a partner or social support during pregnancy, relationship problems, history of abuse or trauma, stressful life events, financial stress, including poverty, substance abuse, indecisive feeling about your pregnancy, previous pregnancy losses or abortions, anxiety about 
the fetus, such as from having pregnancy complications, unplanned pregnancy. ${ }^{18,19}$

Depressed pregnant women are more likely to develop various complications, including severe nausea and vomiting, and preeclampsia than non depressed pregnant women. Women with ante partum depression are also at higher risk for postpartum depression, which occurs after about 15 percent of births, according to the National Institute of Mental Health.

Ante partum depression if left untreated, in mother may harm fetus by increasing risk of complications during pregnancy leading to delivering a low-birthweight baby, preterm delivery etc. ${ }^{20}$ Depression and its symptoms are related to restricted fetal growth and pre mature deliveries, some studies have linked fetal malformations, cardiac defects, pulmonary hypertension, and reduced birth weight to antidepressant use during pregnancy. An increased risk of persistent pulmonary hypertension (PPHN) was found among newborns whose mothers were treated with SSRIs with a greater risk for infants who were exposed later in pregnancy.

Ante partum depression can be well treated using specific techniques such as cognitive behavioral therapy (CBT), interpersonal psychotherapy, support groups, brain stimulation therapies, electroconvulsive therapy (ECT), practicing yoga and exercise.

The UK National Institute for Health and Clinical Excellence (NICE) $)^{21}$ has proposed in their antenatal and postnatal mental health guidelines that health professionals should consider exercise as a management strategy in women experiencing mild-to-moderate depression.

Hence, present study is being conducted at outpatient unit of obstetrics and gynecology at Durgabai Deshmukh hospital and research Centre. After taking permission from hospital authority to know the prevalence of Ante partum depression in various trimester among the pregnant women attending outpatient department using Edinburgh Postnatal Depression Scale questionnaire (EPDS). ${ }^{22-24}$

\section{Materials and Methods}

Study Site: Out-patient department of Obstetrics and Gynecology at Durgabai Deshmukh hospital and research center, Vidyanagar, Hyderabad.

Study Design: A Prospective, observational, crosssectional study.

Study Population: All the pregnant women who visits outpatient unit of Obstetrics and Gynecology at Durgabai Deshmukh hospital and research centre for antenatal check-up will be included after satisfying inclusion and exclusion's criteria and give consent for the study.

Study Period: April 2016 to November 2016.

Inclusion Criteria: All the pregnant women attending outpatient department who are willing to participate in the study
Exclusion Criteria: Who are not willing to give informed consent were taken as not willing to participate in the study.

Sample Size: Sample size is calculated by Open Source Epidemiologic Statistics for Public Health. Standard population size is taken as 1 million. Anticipated frequency of occurrence is taken as $24 \%$ (Aberau Birtau et al, ${ }^{4}$ Mina $\mathrm{S}$ et al. ${ }^{25}$ Confidence limits taken as $5 \%$, Design effect taken as 1 . The sample size is taken as 300 with $95 \%$ confidence level.

\section{Methodology}

After Institutional Ethics Committee approval and with consent of pregnant women fulfilling inclusion criteria, all the pregnant women attending antenatal clinic in Durgabai Deshmukh Hospital and Research Centre has been interviewed with The Edinburgh Postnatal Depression Scale questionnaire to know prevalence of ante partum depression.

The Edinburgh Postnatal Depression Scale (EPDS) is a set of 10 screening questions that indicates whether they have symptoms that are common in women with depression and anxiety during pregnancy and in the year following the birth of a child. To complete this set of questions, women had to select the number next to the response that comes closest to how they have felt in the past seven days. The total score was calculated by adding the numbers they selected for each of the 10 items.

Scoring: Questions 1, 2, \& 4 are scored $0,1,2$ or 3 with top box scored as 0 and the bottom box scored as 3.

Questions 3, 5-10 are reverse scored, with the top box scored as a 3 and the bottom box scored as 0 . Maximum score: 30. Always look at item 10 (suicidal thoughts) EPDS score $\geq 13$ was taken as depression. ${ }^{2}$ 


\section{Edinburgh Postnatal Depression Scale ${ }^{1}$ (EPDS)}

Name:

Your Date of Birth:

Baby's Date of Birth:
Address:

Phone:

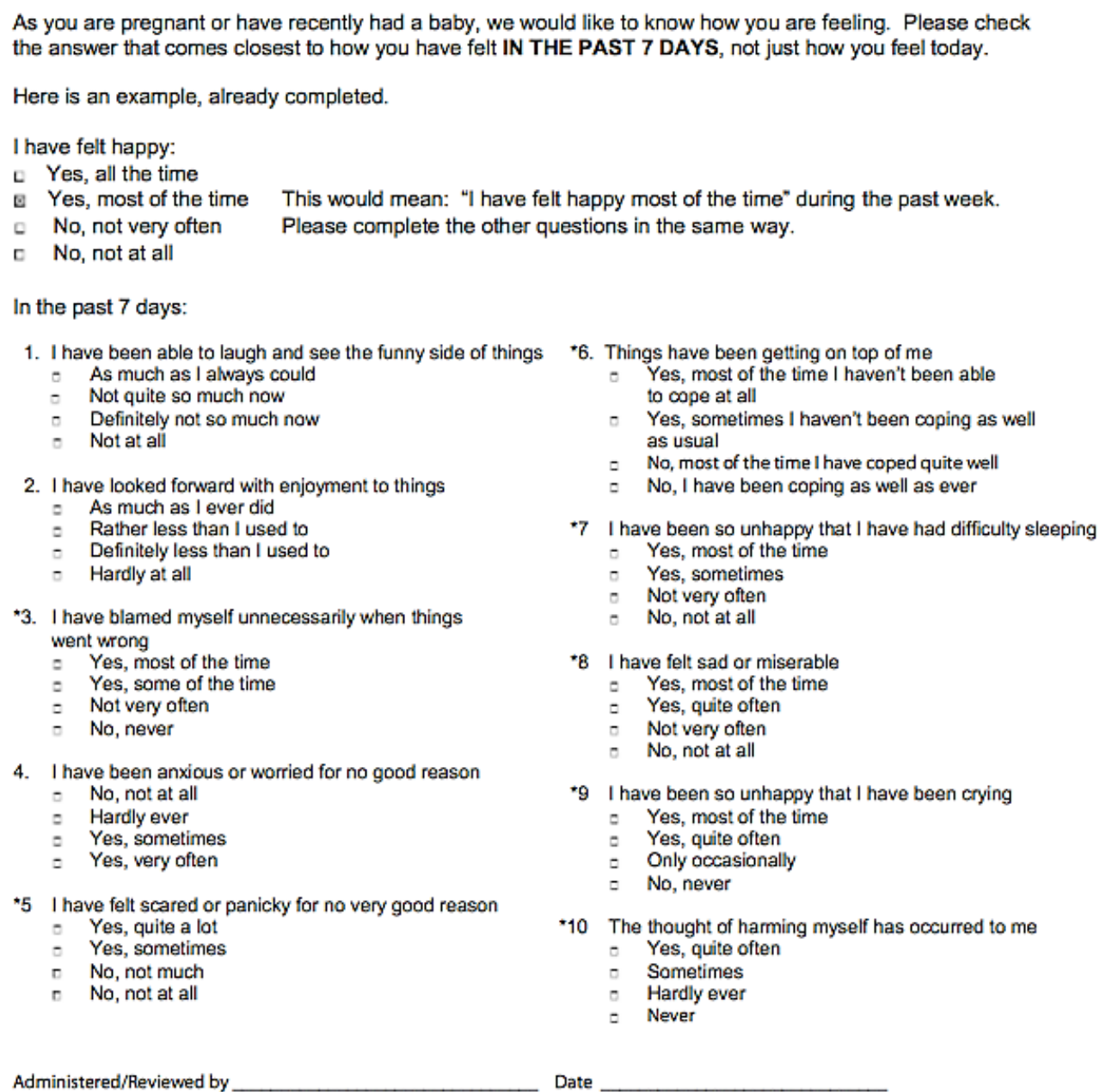

\section{Statistical Data Analysis}

After collecting the data, the statistical analysis has been done by applying.

B. Inferential statistics- a) chi-square test, b) / Z test/ ANNOVA test.

C. SPSS $19^{26}$ version or EXCEL software will be used for the statistical analysis.

Data was analyzed using SPSS 17 software. Results were considered significant when $p<0.05$. Microsoft word and Excel have been used to generate graphs, tables etc.

\section{Results}

68 of 300 subjects had APD i.e., 22.66\% is the prevalence of APD in the selected group of subjects. Majority(56\%)belong to the age group of 25-30 years, of which $29.16 \%$ had APD. $3 \%$ of 300 subjects had poor family support, of which $66.66 \%$ had APD. $3 \%$ had partner violence, of which $66.66 \%$ had APD. $4 \%$ were from upper lower SES, of which $41.66 \%$ had APD. $24.66 \%$ were from rural area, of which $28.37 \%$ had APD. 57\% were primigravida, of which $23.39 \%$ had APD. $11.33 \%$ were less than 14 weeks of GA, of which $26.47 \%$ had APD. 9\% had obstetric risk factors, of which $26.32 \%$ had APD. Among the seven factors observed, only 3 factors i.e., age group ( $p=0.003062$ ), poor family support $(\mathrm{p}=0.001369)$ and partner violence $(\mathrm{p}=0.001369)$ were statistically significant. 
Table 1: Age distribution

\begin{tabular}{|l|c|c|}
\hline \multicolumn{1}{|c|}{ Age } & No. of Pregnant women (\%) & Women with APD (\%) \\
\hline $19-24$ & $104(34.66)$ & $18(26.47)$ \\
\hline $25-30$ & $168(56)$ & $49(72.05)$ \\
\hline$>30$ & $28(9.33)$ & $1(1.47)$ \\
\hline Total & 300 & 68 \\
\hline
\end{tabular}

Table 2: Distribution according to gestational age

\begin{tabular}{|l|c|c|}
\hline Gestational age & No of women (\%) & Women with APD (\%) \\
\hline$<13$ & $34(11.33)$ & $9(26.47)$ \\
\hline $13-28$ & $115(38.33)$ & $28(24.34)$ \\
\hline$>28$ & $151(50.33)$ & $31(20.52)$ \\
\hline Total & 300 & 68 \\
\hline
\end{tabular}

Table 3: Distribution according to parity

\begin{tabular}{|l|c|c|}
\hline Gravida & No. of Pregnant women (\%) & Women with APD (\%) \\
\hline Primi & $171(57)$ & $40(23.39)$ \\
\hline Multi & $129(43)$ & $28(21.70)$ \\
\hline Total & 300 & 68 \\
\hline
\end{tabular}

Table 4: Distribution of risk factors

\begin{tabular}{|l|c|c|}
\hline \multicolumn{1}{|c|}{ Risk Factor } & No of Women (\%) & Women with APD (\%) \\
\hline CHTN & $1(0.33)$ & 0 \\
\hline GHTN & $24(8)$ & $6(25)$ \\
\hline GHTN+OLIGO & $1(0.33)$ & $1(100)$ \\
\hline Hypothyroidism & $18(6)$ & $5(27.77)$ \\
\hline Hypothyroidism+GHTN & $2(0.66)$ & $1(50)$ \\
\hline Hypothyroidism+Twins & $1(0.33)$ & $1(100)$ \\
\hline GDM+POLY+RH NEG & $1(0.33)$ & $1(100)$ \\
\hline GDM & $1(0.33)$ & 0 \\
\hline MILD PE & $1(0.33)$ & 0 \\
\hline GDM+Hypothyoidism & $3(1)$ & 0 \\
\hline Mild PE+Hypothyroidism & $1(0.33)$ & 0 \\
\hline Oligohydramnios & $2(0.66)$ & 0 \\
\hline H/O Anxiety Disorder & $1(0.33)$ & 0 \\
\hline None & $243(81)$ & $53(21.81)$ \\
\hline
\end{tabular}

\section{Discussion}

Our study adds to the sparse literature about depression in pregnancy among Indian population, we assessed the prevalence of depression during pregnancy (using EPDS) and its association with certain obstetric and socio-demographic risk factors.

The previous 159 studies conducted used 24 different depression screeners, with the center for epidemiological studies depression scale $(31.4 \%)$, the edinburgh postnatal depression scale $(18.2 \%)$, and the beck depression inventory (17.0\%) being the most common. Only 20 studies (12.6\%) used a formal diagnostic assessment for depression. But among the scales mentioned above, most commonly used scale being the centre for epidemiological studies depression scale, but it is for the depression and suicidal tendencies in general population. ${ }^{28}$ Hence, EPDS has been chosen for the present study.
Most previous studies have used an EPDS score $\geq 10-14$ as a proxy for depression. In this study EPDS $\geq 13$ is taken as measure for depression. ${ }^{24}$ Prevalence estimates of depression in pregnancy differ substantially across studies, likely attributable to population heterogeneity, but also due to methodological differences such as choice of measurement. $^{5}$ 
Table 5

\begin{tabular}{|l|c|}
\hline \multicolumn{1}{|c|}{ Study } & Prevalence \\
\hline Present Study $(2016)$ & $22.66 \%(95 \%$ CI,17.9,27.4) \\
\hline Amar D Bavle et al $(2016)^{3}$ & $12.3 \%(95 \%$ CI,8.7,15.9) \\
\hline Biratu A et al $(2015)^{4}$ & $24.94 \%(95 \%$ CI,20.85,29.3) \\
\hline Ajinkya S et al $(2013)^{6}$ & $9.18 \%(95 \%$ CI,5.02,13.34) \\
\hline Mina S et al $(2012)^{25}$ & $17 \%(95 \%$ CI,9.6,24.4) \\
\hline Bowen A et al $(2006) 7$ & $27 \%(95 \%$ CI,13.1,40.9) \\
\hline
\end{tabular}

As per Indian statistics, many of the published results yet are based on postpartum depression. Very few studies were published on APD which show the prevalence of depression during pregnancy and was found to be $9.18 \%$ in a tertiary care hospital in Navi Mumbai ${ }^{6}{ }^{12.3 \%}$, Bangalore, ${ }^{3} 16.3 \%$ in Kerala and Tamil $\mathrm{Nadu}^{22}$ in our study result of prevalence is $22.66 \%$ which is similar.

A recent Cochrane meta-analysis of 21 studies $^{29}$ shows that the prevalence of depression in pregnancy ranged from $7.4 \%$ in the first trimester to a high of $12.8 \%$ in the second trimester, with a mean prevalence rate of $10.7 \%$.

Prevalence of antenatal depression in Abeokuta North LGA is high at $24.5 \%$. It peaked in the first trimester and slightly decreased with increasing trimester, which is similar to our study.

Pronouncement from a recent meta-analysis report conducted on over 14,000 subjects found depression during pregnancy as one of the strongest predictor of postpartum depression. ${ }^{27}$

To preclude postpartum depression, detecting the risk factors prior and intervening early might be of help.

The uncertainty of suicide in the ante partum period has been ingrained and determined as one of the leading causes of maternal death in western world ${ }^{10}$ and it's also showing increasing trend in India also ${ }^{11}$ Infants unprotected to antenatal anxiety and depression have been found to be highly reactive, exhibit poorer interactions with their mothers.

During this period of study 300 women were assessed for presence of symptoms suggestive of ante partum depression using EPDS questionnaire.

In this study $168(56 \%), 104(34.66 \%)$ and 28 $(9.33 \%)$ of women were from age group of $25-30 \mathrm{yrs}$, 19-24yrs,>30yrs respectively. 18(17.3\%), 49(29.16\%) and $1(3.57 \%)$ of women were found to be having ante partum depression respectively.

$80(26.66 \%), 100(33.33 \%), 96(32 \%), 12(4 \%)$ and $12(4 \%)$ of women belonged to upper class, upper middle, lower middle, upper lower and lower socio economic class according to Modified Kuppuswamy classification. Of these 14 (17.5\%), 23 (23\%), 25 (26.04\%), 5(41.66\%) and $1(8.33 \%)$ of women were found to be having ante partum depression respectively.

237 (79\%), $59(19.66 \%)$ and $4(1.33 \%)$ of women were homemaker, working and studying, among them $55(23.20 \%), 13(22.03 \%)$ and $0 \%$ of women were found to be having ante partum depression respectively.
$32(10.66 \%), \quad 52(17.33 \%), \quad 130(43.33 \%)$ and $86(28.66 \%)$, of pregnant women were studied up to $<$ SSC, SSC -Inter, Bachelor and Master respectively. Of these, 5(15.62\%), 11(21.15\%), 33(25.38\%), 19

(22.09\%) of women developed ante partum depression respectively.

$16(5.33 \%), \quad 125(41.66 \%), \quad 101(33.66 \%)$, $50(16.66 \%), 7(2.33 \%)$ and $1(0.33 \%)$ pregnant women were having BMI in range of $<18.5,18.5-24.9,25-29.9$, $30-35,>35$ and $>40$ respectively. Of these, $4(25 \%)$, $28(22.4 \%), 23(22.77 \%), 11(22 \%), 2(28.57 \%)$ and $0(0 \%)$ pregnant women developed ante partum depression respectively.

$226(75.33 \%)$ and $74(24.66 \%)$ women were belonging to urban and rural region. Of these, $47(20.79 \%)$ and $21(28.37 \%)$ women were having ante partum depression respectively.

$171(57 \%)$ and $129(43 \%)$ women were primi and multigravida respectively. Of these, $40(23.39 \%)$ and $28(21.70 \%)$ women developed antepartum depression respectively.

$34(11.33 \%), \quad 115(38.33 \%)$ and 151(50.33\%) women were belonging to gestational age of less than $13,13-28$ and more than 28. Of these, $9(26.47 \%)$, $28(24.34 \%)$ and $31(20.52 \%)$ women were having antepartum depression respectively.

$267(89 \%), 23(7.66 \%)$ and $10(3.33 \%)$ women were belonging to Hindu, Muslim and Christian religion. Of these, 62(23.22\%), 3(13.04\%) and 3(30\%) women were having antepartum depression respectively.

291(97\%) women were having family support while $9(3 \%)$ women's family were not supportive. Of these, 62(21.30\%) and 6(66.66\%) women developed antepatum depression respectively.

The prevalence of depression during pregnancy in this study was found to be $22.66 \%$ ( $n=68$ ), which was on the upper side of the $5 \%$ to $25 \%$ prevalence of antenatal depressive symptoms reported by several other studies with different rating scales.

In this study Age group (25-30yrs, OR-11.2), Poor family support (OR-7.4) and partner violence (OR-7.4) are statistically proven to be a risk factor for development of ante partum depression. 
Table 6

\begin{tabular}{|l|l|}
\hline \multicolumn{1}{|c|}{ Risk Factor } & Odds Ratio (95\% CI) \\
\hline $\begin{array}{l}\text { Age of mother (25- } \\
\text { 30yrs) }\end{array}$ & $11.2(95 \%$ CI:1.5-84.1 \\
\hline Poor Family support & $7.4(95 \%$ CI:1.8-30.4) \\
\hline Partner violence & $7.4(95 \%$ CI:1.8-30.4) \\
\hline
\end{tabular}

Maternal anxiety, life stress, history of depression, lack of social support, unintended pregnancy, domestic violence, lower income, lower education, smoking, single status, and poor relationship quality were associated with a greater likelihood of ante partum depression symptoms in bivariate analyses.

In summary, our study has shown that depression during pregnancy was common with several risk factors found to be associated with it. Future research in this area is needed with diagnostic and psychiatric clinical interview to clearly elucidate the potential short-term and long-term impact of depression during pregnancy and associated obstetric risk factors. Hence, we recommend that screening for depression should be a part of the routine antenatal checkups so that women in need of intervention can be detected and treated early to prevent adverse outcomes.

\section{Conclusion}

Antepartum depression is a largely undetected public health problem in our country. There is lack of awareness among care givers and obstetricians. It has a significant maternal and neonatal morbidity hence prompt recognition and treatment is essential. Universal screening for antepartum depression must be incorporated into our maternal and child health programmes.

The risk of suicide in the antepartum period has been well established and identified as one of the leading causes of maternal death in western world ${ }^{10}$ and is showing increasing trend in India also. ${ }^{11}$

Infants exposed to antenatal anxiety and depression has been found to be highly reactive, exhibit poorer interactions with their mothers.

Obstetrician must be aware of the symptoms, need to identify them early and treat to prevent maternal morbidity. Women need to be counselled, followed up promptly to identify its progression to depression and given adequate counselling to prevent postpartum depression'.

Limitations of Study: In spite of the efforts taken, there are few limitations of this study.

Follow up and period prevalence was not possible due to the nature of the cross-sectional design.

This was a relatively small survey conducted only in OPD of one hospital. Thus, there is a need to investigate in other settings within the country where health facilities may be more constrained.

Edinburg postnatal depression score which was used allows us to examine only for the current (preceding 2 weeks) prevalence of depression and we do not know whether the onset of depression was prior to the current pregnancy.

With limited time period and moderate sample size, it was not feasible to conduct a full diagnostic, psychiatric clinical interview of all the patient and assessment for other possible co-morbid diagnoses such as anxiety disorders or other psychosocial factors, which could affect antenatal psychological wellbeing.

Due to sensitive nature of this study, the respondent's honesty and disclosure might be constrained. However, we tried to minimize this bias by building a good rapport by ensuring confidentiality and privacy.

Recommendations: Health care provider should increase awareness of depression and mood disorders in pregnant women.

We should screen pregnant women at least once during the antepartum period for depression using a standardized, validated tool like EPDS.

Women with current depression or anxiety, a history of perinatal mood disorders, or risk factors for perinatal mood disorders warrant particularly close monitoring, evaluation, and assessment.

Clinical staff in obstetrics and gynaecology practices should be prepared to initiate medical therapy, refer patients to appropriate behavioural health resources or psychiatrist when indicated and followed up properly.

\section{References}

1. American College of Obstetricians and Gynecologists Committee opinion no. 343; psychosocial risk factors: perinatal screening and intervention. Obstet Gynecol. 2006;108:469-77.

2. Gaynes BN, Gavin N, Meltzer-Brody S, Lohr KN, Swinson T, Gartlehner G, et al. Perinatal depression: prevalence, screening accuracy, and screening outcomes. Evid Rep Technol Assess (Summ). 2005;(119):1-8.

3. Bavle AD, Chandahalli AS, Phatak AS, Rangaiah N, Kuthandahalli SM, Nagendra PN. Antenatal Depression in a Tertiary Care Hospital. Indian J Psych.

4. Biratu A, Haile D. Prevalence of antenatal depression and associated factors among pregnant women in Addis Ababa, Ethiopia: a cross-sectional study. Reprod Health. 2015;12(1):99.

5. Bennett $\mathrm{H}$ a, Einarson A, Taddio A, Koren G, Einarson TR. Prevalence of depression during pregnancy: systematic review. Obstet Gynecol. 2004;103(4):698 709.

6. Ajinkya S, Jadhav PR, Srivastava NN. Depression during pregnancy: Prevalence and obstetric risk factors among pregnant women attending a tertiary care hospital in Navi Mumbai. Ind Psychiatry J. 2013;22(1):37-40.

7. Bowen A, Muhajarine N. Prevalence of antenatal depression in women enrolled in an outreach program in Canada. J Obstet Gynecol Neonatal Nurs. 2006;35(4):491-8.

8. Cooper WO, Willy ME, Pont SJ, Ray WA. Increasing use of antidepressants in pregnancy. Am J Obstet Gynecol. 2007;196(6):544.

9. Shidhaye P. Maternal depression: A hidden burden in 
developing countries. Ann Med Health Sci Res. 2014; 4(4):463-465.

10. Oates M. Suicide: the leading cause of maternal death. $\mathrm{Br}$ J Psychiatry. 2003;183: 279-81.

11. Supraja TA, Thennarasu K, Satyanarayana VA, Seena TK, Desai G, Jangam K V., et al. Suicidality in early pregnancy among antepartum mothers in urban India. Arch Womens Ment Health. 2016;19(6):1101-1108.

12. Newport DJ, Levey LC, Pennell PB, Ragan K, Stowe ZN. Suicidal ideation in pregnancy: Assessment and clinical implications. Arch Womens Ment Health. 2007;10(5):181-7

13. Jesse DE, Swanson MS. Risks and resources associated with antepartum risk for depression among rural southern women. Nurs Res. 2007;56(6):378-86.

14. Fung J, Gelaye B, Zhong Q-Y, Rondon MB, Sanchez SE, Barrios Y V, et al. Association of decreased serum brainderived neurotrophic factor (BDNF) concentrations in early pregnancy with antepartum depression. $B M C$ Psychiatry. 2015;10;15:43.

15. Glazier RH, Elgar FJ, Goel V, Holzapfel S. Stress, social support, and emotional distress in a community sample of pregnant women. J Psychosom Obstet Gynaecol. 2004;25(3-4):247-55.

16. Gelaye B, Barrios Y V., Zhong QY, Rondon MB, Borba CPC, Sánchez SE, et al. Association of poor subjective sleep quality with suicidal ideation among pregnant Peruvian women. Gen Hosp Psychiatry. 2015;37(5):4417.

17. Records K, Rice M. Psychosocial correlates of depression symptoms during the third trimester of pregnancy. $J$ Obstet Gynecol Neonatal Nurs. 2007;36(3):231-42.

18. Whisman M a, Davila J, Goodman SH. Relationship adjustment, depression, and anxiety during pregnancy and the postpartum period. J Fam Psychol. 2011;25(3):37583.

19. Jesse DE, Blanchard A, Bunch S, Dolbier C, Hodgson J, Swanson MS. A pilot study to reduce risk for antepartum depression among women in a public health prenatal clinic. Issues Ment Health Nurs. 2010;31(5):355-64.

20. Waters CS, Hay DF, Simmonds JR, van Goozen SHM. Antenatal depression and children's developmental outcomes: potential mechanisms and treatment options. Eur Child Adolesc Psychiatry. 2014;23(10):957-71.

21. Howard LM, Megnin-Viggars O, Symington I, Pilling S.
Antenatal and postnatal mental health: summary of updated NICE guidance. BMJ. 2014;18:349:g7394.

22. Töreki A, Andó B, Keresztúri A, Sikovanyecz J, Dudas RB, Janka Z, et al. The Edinburgh Postnatal Depression Scale: Translation and antepartum validation for a Hungarian sample. Midwifery. 2013;29(4):308-15.

23. Gibson J, McKenzie-Mcharg K, Shakespeare J, Price J, Gray R. A systematic review of studies validating the Edinburgh Postnatal Depression Scale in antepartum and postpartum women. Acta Psychiatr Scand. 2009;119(5):350-64.

24. Rubertsson C, Börjesson K, Berglund A, Josefsson A, Sydsjö G. The Swedish validation of Edinburgh Postnatal Depression Scale (EPDS) during pregnancy. Nord $J$ Psychiatry. 2011;65(6):414-8.

25. Mina S, Singh Balhara YP, Verma R, Mathur S. Study of anxiety and depression in antepartum and post partum period. Indian J Psychiatry. 2012;54:95.

26. Sunder Rao P S S, Richard J. An Introduction to Biostatistics. A manual for students in health sciences. 4th edition. New Delhi: Prentice hall of India. 2006:86160.

27. Ongeri L, Otieno P, Mbui J, Juma E, Mathai M (2016) Antepartum Risk Factors for Postpartum Depression: A Follow up Study among Urban Women Living in Nairobi, Kenya. J Preg Child Health. 3:288. doi:10.4172/2376-127X.1000288

28. Dennis CL, Allen K. Interventions (other than pharmacological, psychosocial or psychological) for treating antenatal depression. Cochrane Database Syst Rev. 2008;(4):CD006795.

29. Westdahl C, Milan S, Magriples U, Kershaw TS, Rising SS, Ickovics JR Obstet Gynecol. 2007;110(1):134-40.

30. Bernazzani O, Saucier JF, David H, Borgeat F, et al. 2000;59(1):31-40.

How to cite this article: Garlapati R, Dharani D.K.R, Rao M, Tejaswini. A cross sectional study to analyse the pervasiveness and risk factors of antepartum depression in pregnant women. Ind $\mathbf{J}$ Obstet Gynecol Res. 2018;5(3):365-371. 